\title{
Odontogenic Cysts, Odontogenic Tumors, Fibroosseous, and Giant Cell Lesions of the Jaws
}

\author{
Joseph A. Regezi, D.D.S., M.S. \\ Oral Pathology and Pathology, Department of Stomatology, University of California, San Francisco, \\ San Francisco, California
}

Odontogenic cysts that can be problematic because of recurrence and/or aggressive growth include odontogenic keratocyst (OKC), calcifying odontogenic cyst, and the recently described glandular odontogenic cyst. The OKC has significant growth capacity and recurrence potential and is occasionally indicative of the nevoid basal cell carcinoma syndrome. There is also an orthokeratinized variant, the orthokeratinized odontogenic cyst, which is less aggressive and is not syndrome associated. Ghost cell keratinization, which typifies the calcifying odontogenic cyst, can be seen in solid lesions that have now been designated odontogenic ghost cell tumor. The glandular odontogenic cyst contains mucous cells and ductlike structures that may mimic central mucoepidermoid carcinoma. Several odontogenic tumors may provide diagnostic challenges, particularly the cystic ameloblastoma. Identification of this frequently underdiagnosed cystic tumor often comes after one or more recurrences and a destructive course. Other difficult lesions include malignant ameloblastomas, calcifying epithelial odontogenic tumor, squamous odontogenic tumor, and clear-cell odontogenic tumor. Histologic identification of myxofibrous lesions of the jaws (odontogenic myxoma, odontogenic fibroma, desmoplastic fibroma) is necessary to avoid the diagnostic pitfall of overdiagnosis of similar-appearing follicular sacs and dental pulps. Fibroosseous lesions of the jaws show considerable microscopic overlap and include fibrous dysplasia, ossifying fibroma, periapical cementoosseous dysplasia, and low-grade chronic osteomyelitis. The term fibrous dysplasia is probably overused in general practice and should be reserved for the rare lesion that presents as a large, expansile, diffuse opacity of children and young adults. The need to use clinicopath-

Copyright (C) 2002 by The United States and Canadian Academy of Pathology, Inc.

VOL. 15, NO. 3, P. 331, 2002 Printed in the U.S.A.

Date of acceptance: September 27, 2001.

Address reprint requests to: Joseph A. Regezi, D.D.S., M.S., 513 Parnassus, S-512, University of California, San Francisco, San Francisco, CA 941430424; e-mail: strnglv@itsa.ucsf.edu; fax: 415-476-6482. ologic correlation in assessing these lesions is of particular importance. Central giant cell granuloma is a relatively common jaw lesion of young adults that has an unpredictable behavior. Microscopic diagnosis is relatively straightforward; however, this lesion continues to be somewhat controversial because of its disputed classification (reactive versus neoplastic) and because of its management (surgical versus. medical). Its relationship to giant cell tumor of long bone remains undetermined.

KEY WORDS: Ameloblastoma, CEOT, Fibrous dysplasia, Giant cell granuloma, Odontogenic keratocyst, Odontogenic myxoma, Odontogenic tumors.

Mod Pathol 2002;15(3):331-341

The jaws are host to a wide variety of cysts and neoplasms, due in large part to the tissues involved in tooth formation. Many benign jaw tumors and several cysts (some recently described), of both odontogenic and nonodontogenic origin, can exhibit a biologically aggressive course and can be diagnostically difficult. Traditional histopathology continues to be the mainstay for the diagnosis of these lesions, as immunohistochemistry and molecular techniques have had, as yet, little impact in this area.

\section{ODONTOGENIC CYSTS OF DIAGNOSTIC SIGNIFICANCE}

\section{Odontogenic Keratocyst}

The odontogenic keratocyst (OKC) is a commonly encountered developmental cyst (Table 1) of considerable importance because of its potential for aggressive clinical behavior and recurrence (1; Fig. 1). Also, it may be a component of the nevoid-basal cell carcinoma (Gorlin) syndrome. OKC occurs anywhere in the jaws and in any position. It may be superimposed over the apices of tooth roots or adjacent to the crowns of impacted teeth. Radiographically, it appears as a well-defined lucency 
TABLE 1. Current Classification of Jaw Cysts
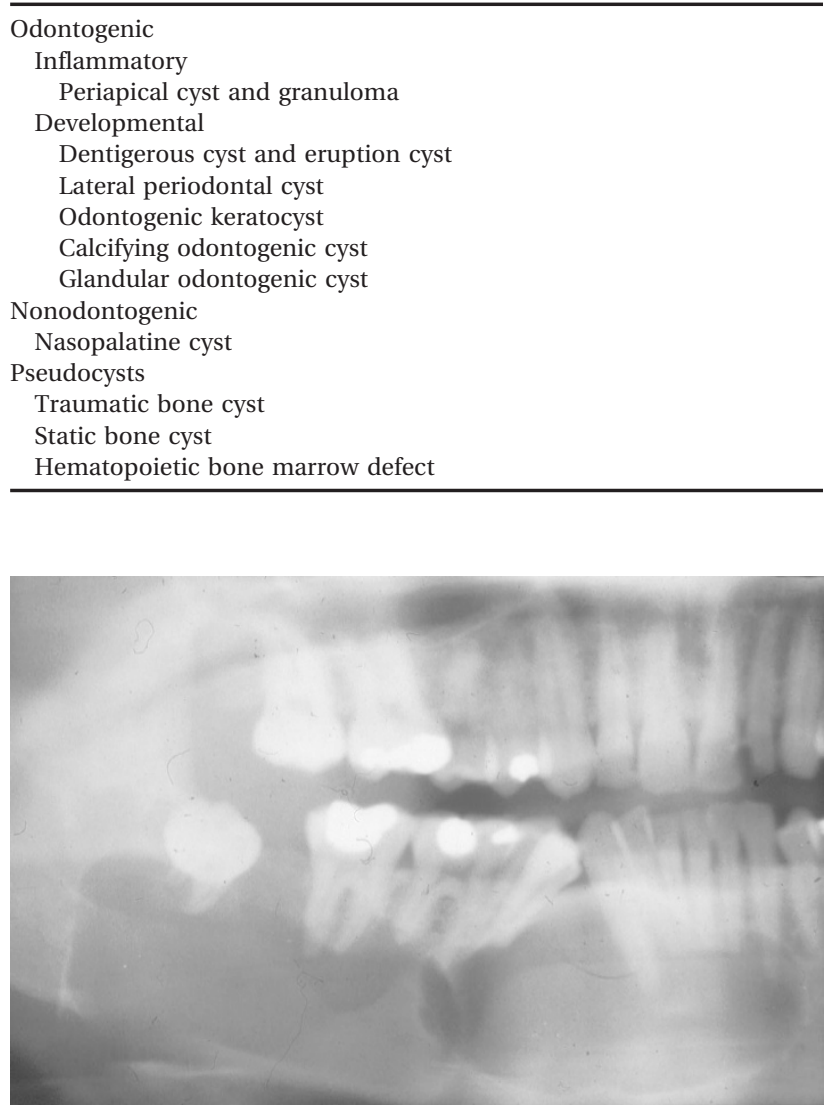

FIGURE 1. Odontogenic keratocyst of the entire right mandibular body.

and is often multilocular. OKCs represent $5-15 \%$ of all odontogenic cysts. The recurrence rate for solitary OKC is $10-30 \%$. Approximately $5 \%$ of OKC patients have multiple jaw cysts (and no syndrome), and their recurrence rate is greater than that for solitary lesions.

Microscopically, the epithelial lining exhibits a characteristic thickness of 6-10 cell layers (Fig. 2). The epithelium shows basal palisading and a thin refractile parakeratinized lining layer. Separation of the epithelium from the thin and uninflamed supporting fibrous wall is often seen. Budding of the basal layer and "daughter cyst" formation are frequently findings. If the cyst wall becomes secondarily inflamed, hyperplasia ensues and the characteristic microscopic pattern disappears. Sampling of large cysts may be important for identifying an underlying OKC that has become secondarily inflamed. The epithelial proliferation rate in the OKC is relatively high, especially in the case of those that are syndrome associated. Other advantageous growth mechanisms of OKCs include Bcl-2, cyclin D1, and MDM2 overexpression (2-4).

There is an orthokeratinized variant known as orthokeratinized odontogenic cyst. It exhibits similar microscopic features, except that it has a granular layer, is orthokeratotic, and has a poorly organized basal layer (5; Fig. 2). It is not syndrome-associated (see below) and seems to exhibit a less aggressive behavior than OKC. Rarely, OKCs may show foci of orthokeratinization in an otherwise parakeratinized lining.

The nevoid-basal cell carcinoma syndrome is inherited as an autosomal dominant trait that consists principally of multiple odontogenic keratocysts, multiple basal cell carcinomas, skeletal anomalies, and cranial calcifications. Syndromeassociated OKCs have the highest recurrence rate and represent approximately $5 \%$ of all OKC patients. Many other syndrome manifestations have been described, including medulloblastoma and other neoplasms. The basal cell carcinomas develop early in life and may number in the tens or hundreds. The most frequently cited skeletal anomaly is bifid rib. Calcified falx is also relatively frequently seen on skull radiograms. This syndrome has been linked to mutations in the PATCHED tumor suppressor gene that encodes a receptor protein that is a component of the hedgehog signaling pathway. Mutations of this gene have been found in syndrome-associated basal cell carcinomas and OKCs (6-9).

\section{Calcifying Odontogenic Cyst}

Calcifying odontogenic cyst (COC) is a developmental cyst that may exhibit occasional aggressive/ recurrent behavior. This is particularly true of an occasionally encountered solid variant that is regarded as a neoplasm and termed odontogenic ghost cell tumor. A very rare malignant variety of odontogenic ghost cell tumor has been reported as odontogenic ghost cell carcinoma. COC shows a predilection for females and the maxilla. It occasionally is seen in the gingiva. It may be unilocular or multilocular and may show areas of opacification because of the partial calcification of keratinized lining cells. The distinctive microscopic feature of this lesion, be it cystic or solid, is "ghost cell" keratinization of the epithelial lining (Fig. 3). The keratin may undergo dystrophic calcification and may incite a foreign-body reaction in the cyst wall, giving it features similar to the pilomatrixoma of skin. Ghost cells alone are not diagnostic, as they may occasionally be seen in other odontogenic tumors, such as ameloblastomas and odontomas.

\section{Glandular Odontogenic Cyst (Sialo-Odontogenic Cyst)}

This is a rare and recently described developmental jaw cyst that may superficially mimic a central muco- 


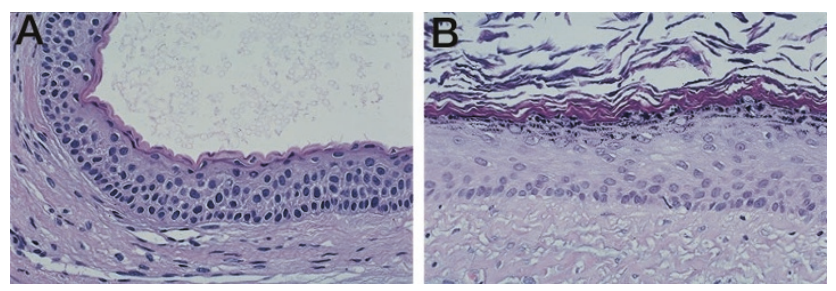

FIGURE 2. Left, odontogenic keratocyst showing thin parakeratinized lining with basal palisading. Separation of epithelium from connective tissue wall is often seen in surgical specimens. Right, orthokeratinized odontogenic cyst showing granular layer and in undistinguished basal layer.

epidermoid carcinoma. It is seen in adults in any jaw site, although anterior regions are favored. This multilocular cyst is lined by nonkeratinized epithelium with focal thickenings composed of mucous cells in a pseudoglandular pattern (Fig. 4). This lesion has shown local aggressiveness and has recurrence potential (10). Dentigerous cysts that exhibit occasional mucous goblet cells in their linings are not believed to be related to the glandular odontogenic cyst. The glandular odontogenic cyst should not be confused with the more exuberant intraluminal lobular proliferation of adenomatoid odontogenic tumor.

\section{DIAGNOSTICALLY CHALLENGING EPITHELIAL ODONTOGENIC TUMORS}

\section{Ameloblastoma}

Ameloblastoma can exhibit one or more microscopic patterns, none of which is of more clinical significance than the others. Peripheral palisading and budding are a common denominator of all subtypes. The most recently described microscopic pattern is one in which there is extensive desmoplasia, and hence, the designation desmoplastic ameloblastoma (Fig. 5). This microscopic subtype is usually seen in the anterior jaws (11). A plexiform microscopic pattern is often seen in association

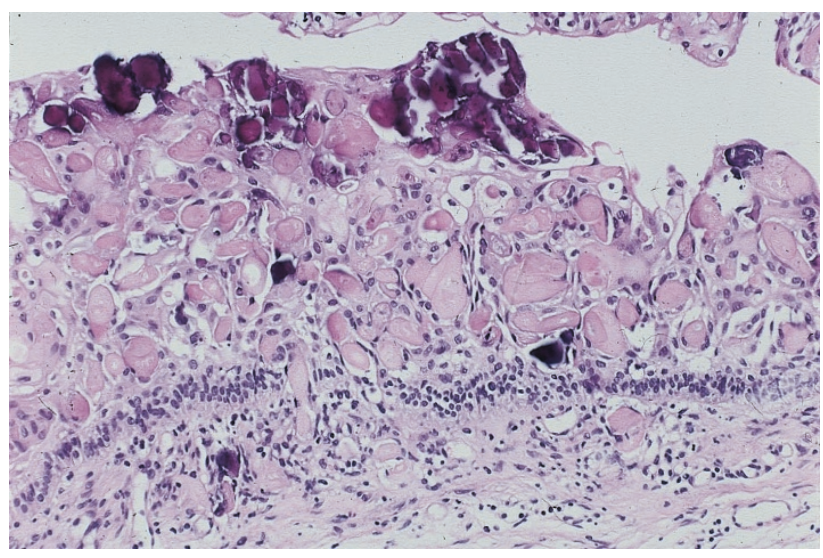

FIGURE 3. Calcifying odontogenic cyst featuring ghost cell keratinization with dystrophic calcification and palisaded basal layer.

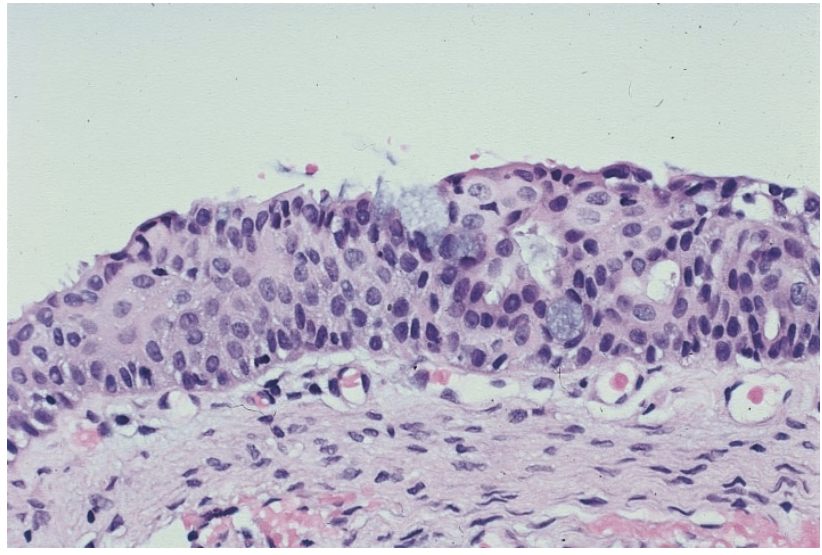

FIGURE 4. Glandular odontogenic cyst represented by a focal thickening in which there is mucin production and small pseudoglandular spaces.

with ameloblastoma of sinonasal origin (12). The appearance of ghost cells, with or without dentinlike islands, in a tumor that otherwise has the appearance of ameloblastoma has prompted the designation of odontogenic ghost cell tumor (13; see COC). The behavior of this rare lesion is believed to be the same as that of ameloblastoma. The growth mechanisms that have been attributed to ameloblastomas have been overexpression of Bcl-2, Bcl-x, and MDM2 proteins. The proliferation index, as determined by Ki67 staining, is unexpectedly low. Expression of fibroblast growth factors, interleukins, and matrix metalloproteinases (MMPs) may account, in part, for the invasive capacity of these tumors (14-23).

\section{Cystic Ameloblastoma}

This biologic subtype of ameloblastoma is also known as unicystic ameloblastoma and, occasionally, as plexiform unicystic ameloblastoma. It was separated from the solid type because it appeared at a younger age, had a lower recurrence rate, and

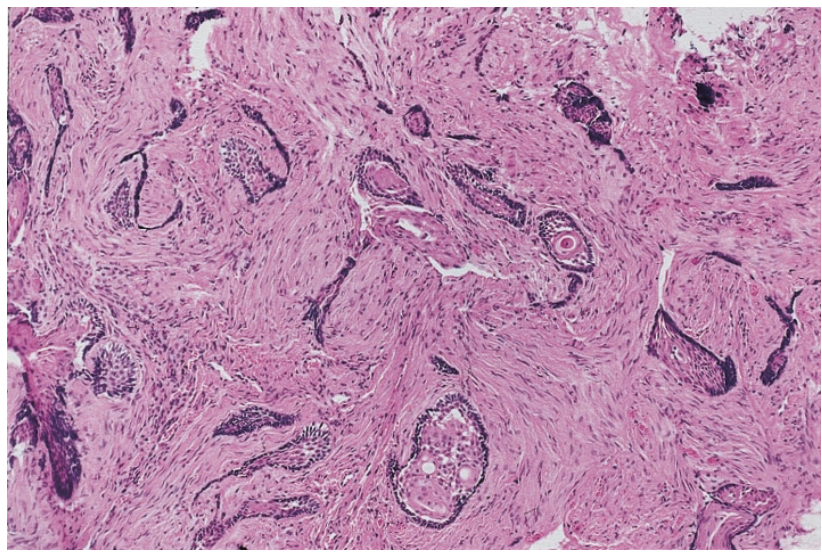

FIGURE 5. Desmoplastic ameloblastoma showing compressed odontogenic epithelial nests in a desmoplastic stroma. 
seemed to require less aggressive surgery (24-27). Recent evidence, however, indicates that cystic ameloblastomas can be destructive and can often recur after simple curettage.

Cystic ameloblastoma usually occurs in the 2nd to 3rd decades and usually in the mandibular molar area. Maxillary lesions are very uncommon. The lesion is entirely cystic and consists usually of a single space, although many have cystic loculations. Radiographically, the lesion is lucent with well-defined margins. It may appear at the apex of a tooth or around the crown of an impacted tooth. It is usually small, although it can reach several centimeters in size. Cystic ameloblastomas have the capacity to expand or perforate jaw cortex (Fig. $6)$.

Microscopically, this is a deceptively innocent appearing lesion that is often underdiagnosed as simple odontogenic cyst. The diagnosis is often made in retrospect when the lesion recurs. The entire cystic epithelial lining represents neoplasm. The reason for the cystic change is unknown, although it may be related to enzymatic destruction of the epithelium by MMPs or serine proteinases. Features that help in microscopic diagnosis include basal cell palisading, epithelial invagination, and epithelial edema and separation (Fig. 7). Mural invasion has been linked to an increased risk of recurrence. Clinicopathologic correlation is helpful.

\section{Malignant Ameloblastomas}

The malignant forms of ameloblastoma have been classified into two subtypes: (1) malignant ameloblastoma, or metastasizing ameloblastoma in which the metastatic lesion microscopically resembles ameloblastoma and (2) ameloblastic carcinoma, in which the primary and metastatic lesions show dedifferentiation and cytologic atypia (Fig. 8; 28-29). There is also another rare malignancy of

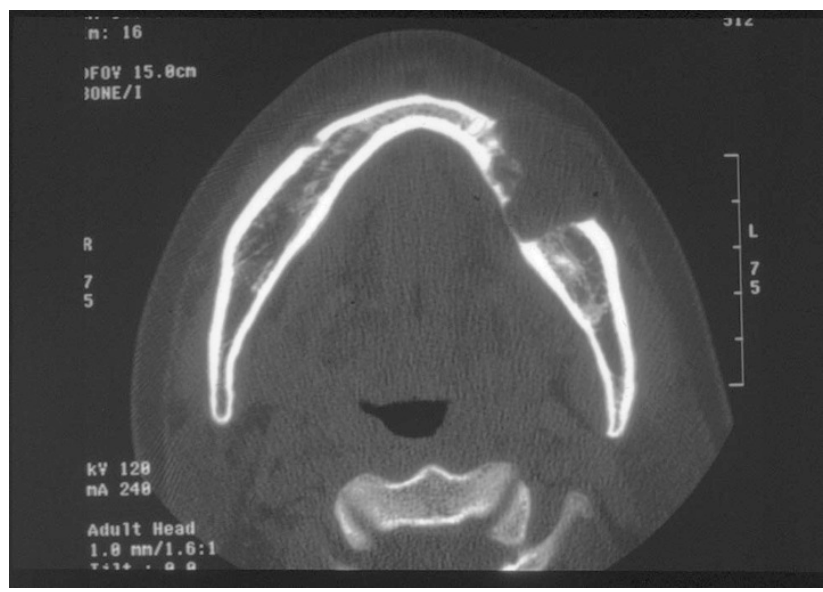

FIGURE 6. Computed tomography scan of a cystic ameloblastoma of the mandible showing cortical penetration.

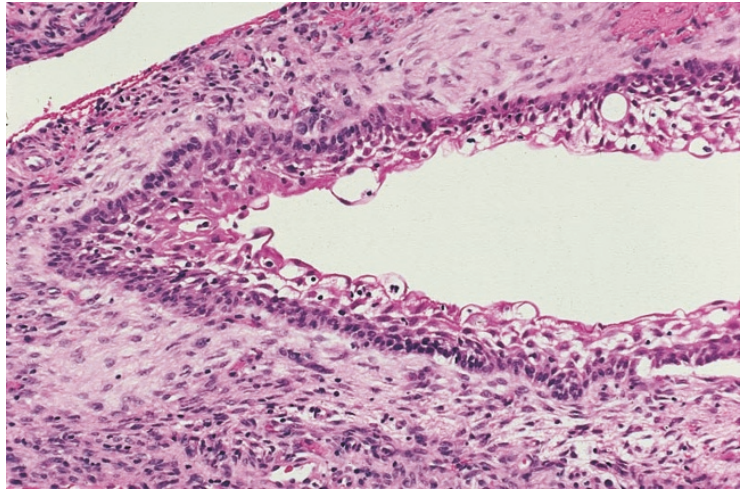

FIGURE 7. Recurrent cystic ameloblastoma. This completely cystic lesion was lined by edematous epithelium with palisaded basal cells.
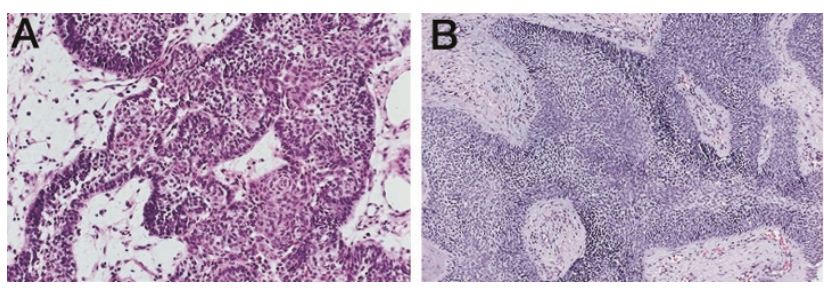

FIGURE 8. Ameloblastic carcinoma. Left, initial lesion in which numerous mitotic figures were found with moderate nuclear atypia. Right, same tumor, now dedifferentiated, after 6 years, several recurrences, and extension to the base of the skull.

odontogenic origin, called primary intraosseous carcinoma, that may occur centrally in the jaws. This lesion, thought to arise from odontogenic rests in bone, looks like squamous cell carcinoma and shows no microscopic features of ameloblastoma.

Malignant ameloblastomas occur at a younger age than their benign counterpart and are usually seen in the mandible. Metastasis is typically to the lung and occasionally to local lymph nodes.

\section{Calcifying Epithelial Odontogenic Tumor}

Also known as Pindborg tumor, calcifying epithelial odontogenic tumor (CEOT) is a rare odontogenic neoplasm of disputed histogenesis. Origin from stratum intermedium-type cells (enamel organ) and dental lamina have been hypothesized. This tumor occurs in the same age range (30-50 years) and in the same jaw sites (posterior mandible favored) as ameloblastoma. It is a slow-growing, benign neoplasm. It may be unilocular or multilocular. Because of focal areas of calcification, the radiographic image occasionally exhibits a mixed lucent-opaque pattern. This tumor rarely occurs in the soft tissues of the gingiva, in which case it is designated as peripheral CEOT. Believed to have a lower recurrence rate than ameloblastoma, CEOT is treated less aggressively than ameloblastoma.

CEOT consists of sheets of large epithelioid cells with zones of amyloid deposits that may show dys- 


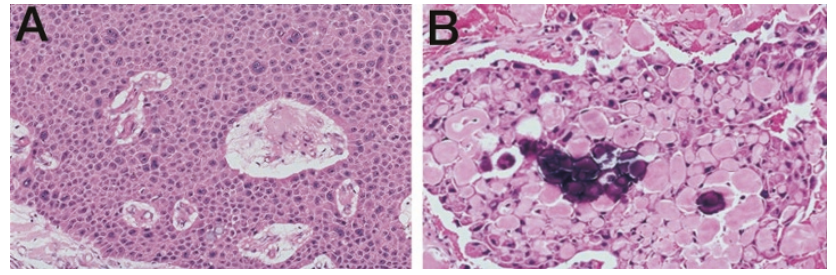

FIGURE 9. Calcifying epithelial odontogenic tumor. Left, sheet of atypical epithelial cells; right, amyloid droplets with dystrophic calcification in epithelial field.

trophic calcification (30; Fig. 9). The amyloid material is an epithelial product (keratins) that stains positive with Congo red and thioflavine T. The tumor cells may exhibit considerable range in nuclear size and shape, but mitotic figures are not seen. The ratio of epithelium to extracellular product can be quite different from one tumor to the next, resulting in a histologic spectrum that ranges from lesions that are composed predominantly of epithelium, to lesions that are composed mostly of extracellular material and relatively little epithelium. Occasionally, the epithelial cells will exhibit clear cytoplasm producing the so-called clear-cell variant of CEOT.

\section{Squamous Odontogenic Tumor}

Squamous odontogenic tumor is a benign odontogenic lesion that can be considered a hamartoma. Because of its presentation in the alveolar process, it is believed to originate (stimulus unknown) from rests of Malassez found in the periodontal ligament. It occurs in the mandible and maxilla with equal frequency and may be multiple. In the alveolar process, it is well circumscribed and is usually associated with the roots of teeth. It is typically small and characteristically appears radiographically as a wedge-shaped lucency at the crest of the alveolar process. As it seems to have limited growth potential, conservative surgical treatment is indicated.

Microscopically, squamous odontogenic tumor appears as islands of bland squamous epithelium (no cellular atypia or mitotic figures) without an inflammatory infiltrate (Fig. 10). Peripheral palisades are not seen. The epithelial islands are occasionally closely associated with bone spicules. There is superficial resemblance to ameloblastoma (acanthomatous type) and well-differentiated squamous cell carcinoma

\section{Clear-Cell Odontogenic Tumor (Carcinoma)}

This is a rare jaw tumor that some consider to be a carcinoma because of reported metastases. The histogenesis is unknown, although it is believed to be derived from odontogenic epithelium because of its primary occurrence in the jaws. Clear-cell odon-

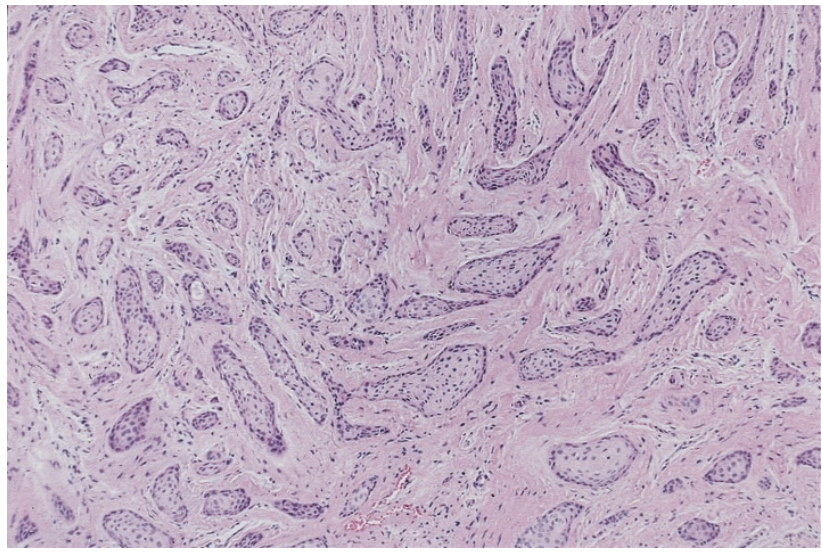

FIGURE 10. Squamous odontogenic tumor exhibiting characteristic bland epithelial islands in a fibrous stroma.

togenic tumor (carcinoma) has been described mostly in women over the age of 60 years. It may cause some pain. Radiographically, the lesion is lucent and either unilocular or multilocular. This rare lesion has an aggressive biologic behavior. Metastases to lung and regional lymph nodes have been reported (31-32).

Microscopically, nests and cords of clear cells are seen (Fig. 11). Some peripheral palisading may be present. Differential diagnosis would include clearcell variant of calcifying epithelial odontogenic tumor, central mucoepidermoid carcinoma, metastatic renal cell carcinoma, and poorly fixed ameloblastoma.

\section{MICROSCOPICALLY SIMILAR MYXOID/FIBROUS JAW TUMORS}

\section{Odontogenic Myxoma}

This benign and sometimes clinically aggressive tumor mimics the dental pulp microscopically. However, immunohistochemical studies have been inconsistent and have not been able to confirm pulp tissue origin (33-35). Odontogenic myxoma

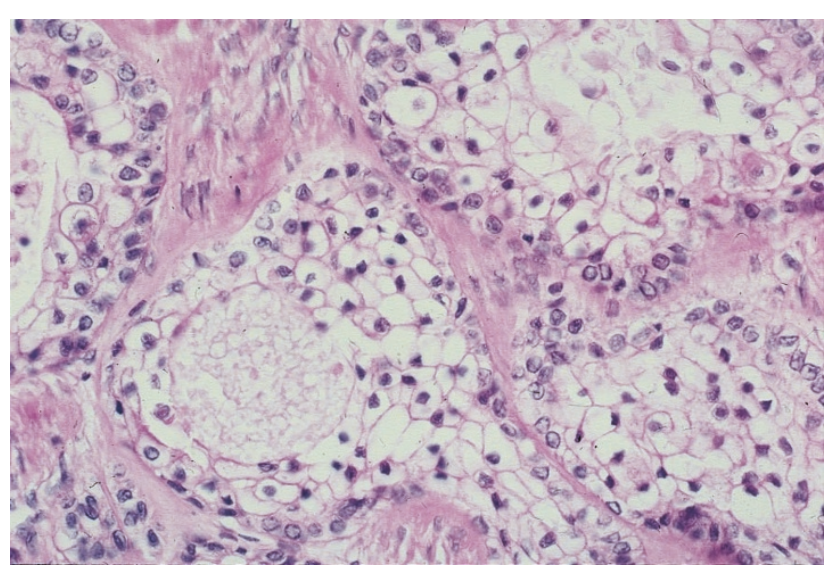

FIGURE 11. Clear-cell odontogenic tumor in nested pattern. 
occurs typically in adults (mean age, 30 years; range, 10-50 years) as a radiolucent lesion, often with small loculations (honeycomb pattern). This jaw neoplasm may exhibit aggressive growth and recurrence.

Odontogenic myxoma has a bland myxoid microscopic appearance (Fig. 12). If collagen is prominent, the designation of myxofibroma or fibromyxoma may be used. Bony islands, representing residual trabeculae, are found throughout the lesion. Odontogenic epithelium is very uncommon in these lesions. If odontogenic rests are found in a myxomatous jaw lesion, follicular sac (normal tissue found around the crowns of unerupted teeth) should be seriously considered (Fig. 12). Reduced enamel epithelium that is a part of the follicular sac residuum is also frequently found along one edge of these specimens. Occasionally, as part of a jaw biopsy, normal dental pulp of a developing tooth may be submitted for microscopic diagnosis. This tissue has the appearance of an odontogenic myxoma except for peripherally positioned columnarshaped odontoblasts. An accurate clinical history and radiographs can be invaluable in separating follicular sac and normal dental pulp from this tumor. Odontogenic myxomas have a low proliferation rate (as determined by Ki67 staining) but overexpress Bcl-2 and Bcl-x proteins. Overexpression of MMP2 protein may contribute to their expansion (unpublished data).

\section{Odontogenic Fibroma}

This jaw tumor is considered a neoplasm that is derived from periodontal ligament or pulp-related fibroblasts. It is a tumor of adults and appears as a well-defined radiolucency in either jaw. It is not, however, particularly aggressive, and it infrequently recurs after simple curettage (36-38).

Microscopically, these lesions are more collagenous than myxomas but may range from myxofibrous to densely fibrous (Fig. 13). Characteristically seen in odontogenic fibromas are few to many islands and strands of bland odontogenic epithelium. Calcific deposits may also be found. A variant (granular cell odontogenic fibroma), in which granular cells are seen in the connective tissue, has been

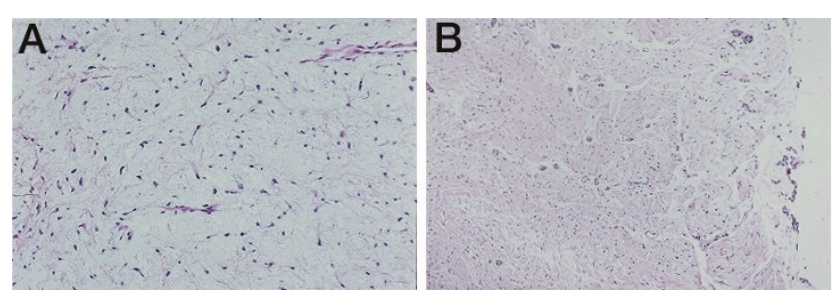

FIGURE 12. Left, odontogenic myxoma. Right, myxoid follicular sac with odontogenic rests. Fragments of reduced enamel epithelium at far right.

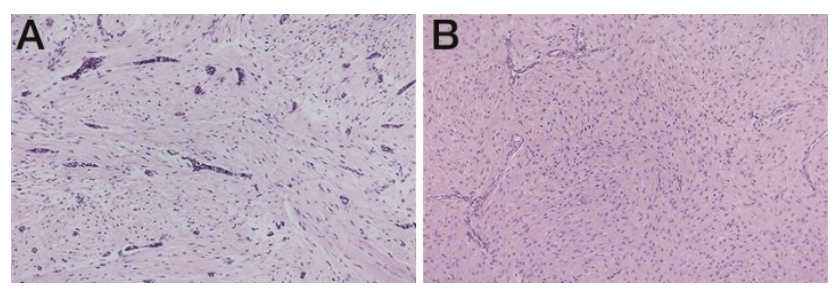

FIGURE 13. Left, odontogenic fibroma of the mandible containing odontogenic rests. Right, desmoplastic fibroma of the mandible composed of evenly distributed and benign fibroblasts in a collagenous stroma.

described. The behavior of this tumor does not appear to be different from odontogenic fibroma. Abundant rest proliferation in follicular sacs can occasionally simulate the appearance of odontogenic fibroma or ameloblastic fibroma. Clinicopathologic correlation is important for the diagnosis of these lesions.

\section{Desmoplastic Fibroma}

This is a rare fibrous lesion of the jaws. It is benign, but aggressive, exhibiting a biologic behavior similar to fibromatosis of soft tissue or lowgrade fibrosarcoma. It is seen in young adults, especially in the mandible. Radiographically, desmoplastic fibroma is lucent, with margins that may be distinct or poorly defined (39-40).

Histologically, these lesions exhibit an interlacing or fascicular growth pattern of benign fibroblasts and collagen. They neither contain epithelial rests nor make bone. Multinucleated giant cells are rarely present. Desmoplastic fibroma should not be confused with central low-grade osteosarcoma which is more cellular and has cytologic atypia.

\section{DIFFERENTIAL DIAGNOSIS OF FIBROOSSEOUS LESIONS OF THE JAWS}

Fibroosseous jaw lesions are a clinically diverse, but histologically similar group of conditions that are characterized microscopically by a benign fibroblastic stroma in which there is new bone deposition. Although ossifying fibromas and fibrous dysplasia are the most conspicuous examples of this group of jaw lesions, other commonly encountered fibroosseous jaw lesions, such as periapical cementoosseous dysplasia and chronic low-grade osteomyelitis, should be considered in differential diagnoses of these lesions. Fibroblastic and central low-grade osteosarcomas of the jaws may occasionally mimic benign fibroosseous lesions. Clinicopathologic correlation is essential for definitive diagnosis of a jaw fibroosseous lesion.

\section{Ossifying Fibroma}

Ossifying fibroma is classified as a benign neoplasm of bone. It is essentially identical to lesions 
that have been designated as cementifying fibroma and cemento-ossifying fibroma. Although the differentiation of ossifying fibroma from fibrous dysplasia may, at times, be difficult, the separation remains important because of differences in treatment and prognosis (41-42).

Ossifying fibroma is a slow-growing, wellcircumscribed lesion that has a predilection for the mandibular body and ramus of the jaw. Usually, it is discovered on routine radiographic exam, though occasionally a patient may complain of facial asymmetry or painless swelling. It is most commonly seen in the third and fourth decades, and women seem to be more frequently affected than men. A variant designated as juvenile ossifying fibroma appears a decade earlier. Lesions in this latter subgroup have also been called active or aggressive juvenile ossifying fibroma. This variant is generally felt to have a greater propensity for recurrence and exhibits aggressive clinical behavior $(43,44)$.

Microscopically, ossifying fibroma is well demarcated from surrounding resident bone. The tumor bone is seen as trabeculae and/or oval (spherical) islands distributed in a relatively uniform pattern throughout the lesion (Fig. 14). Jaw lesions that contain predominantly oval hard-tissue islands, instead of osseous trabeculae, have been referred to as cemento- or psammomatoid-ossifying fibromas. This segregation is essentially academic because the behavior of these lesions are the same. Osteoblasts are usually prominent, typically rimming the new bone, and osteoclasts are scant. Stromal cellularity, which may vary slightly from one area to another, may be relatively high in contrast to fibrous dysplasia. The stroma in the so-called juvenile ossifying fibroma is particularly cellular but is still cytologically benign. The bone in these juvenile lesions appears in the form of strands or trabeculae, although psammomatoid or spheroid islands may be present. With time, ossifying fibromas show continued expansion, with little change microscopically.

\section{Fibrous Dysplasia}

Because of its self-limited growth and apparent responsiveness to the hormonal changes of pu-

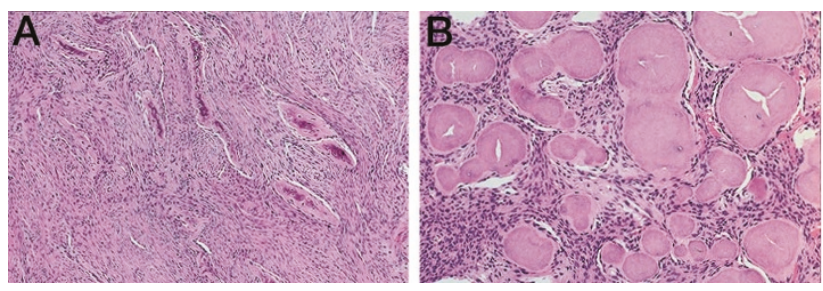

FIGURE 14. Two ossifying fibromas of the mandible showing cellular stromas with trabecular (left) and droplet or psammomatoid (right) bone. berty, fibrous dysplasia is classified as a dysplastic process. It may be limited to one bone (monostotic type), several bones (polyostotic type), or several bones with endocrine abnormalities and pigmented skin macules (McCune-Albright syndrome). It is a self-limiting, slow-growing process that starts in childhood and is usually diagnosed by age 20 years. A diagnosis of fibrous dysplasia of the jaws in an adult should be considered when there is excellent clinicopathologic correlation. Swelling is unilateral and asymptomatic. It exhibits ill-defined margins, blends into surrounding bone, and appears as a diffusely radiopaque lesion with a characteristic "ground glass" image. Although the affected bone may surround teeth, neither looseness or exfoliation are seen. Serum laboratory values are usually within normal limits, unless the patient has extensive polyostotic disease, in which case an elevation of serum alkaline phosphatase may be detected.

In the craniofacial complex, fibrous dysplasia is most commonly seen in the maxilla and calvarium, whereas in the remainder of the skeleton, it is seen in most frequently seen in the rib, femur, and tibia (45). The process usually stabilizes during puberty, persisting in a nearly quiescent state indefinitely. When treatment is necessary to alleviate unacceptable facial deformity, surgical recontouring rather than complete excision is preferred. Regrowth of surgically recontoured fibrous dysplasia is seen in approximately $25 \%$ of cases. Complete or partial excision with bone grafting has been recently used with some success.

Microscopically, fibrous dysplasia consists of a relatively vascular and loose benign fibrous connective tissue stroma surrounding immature fibrillar or woven bony trabeculae (Fig. 15). The stroma generally exhibits only low to moderate cellularity. The incompletely calcified bony trabeculae show some regularity in size and are uniformly distrib-

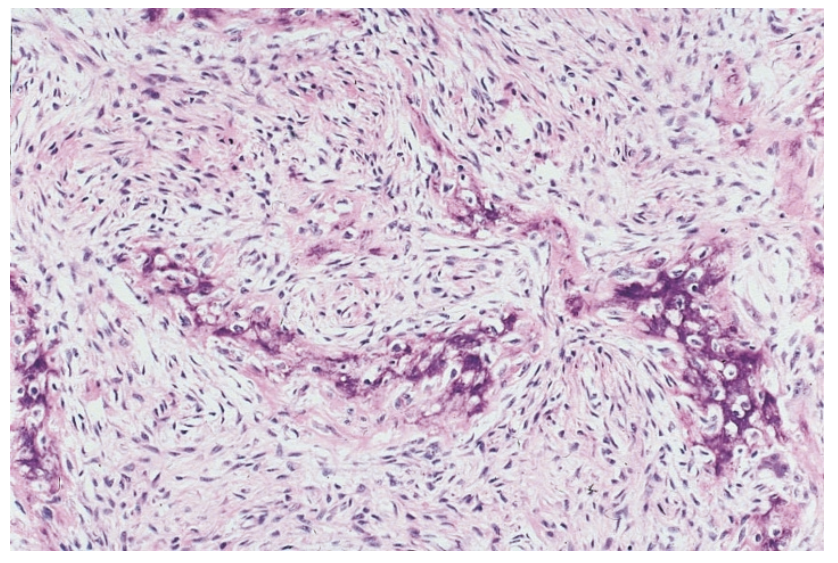

FIGURE 15. Fibrous dysplasia of the jaw showing fibrillar bony trabecular bone that is supposed to be characteristic of this condition. 
uted throughout, gradually blending into normal surrounding bone. Osteoclasts are typically inconspicuous, and osteoblasts are scant, providing an appearance to the tumor bone that has been referred to as osseous metaplasia. As patients with fibrous dysplasia age, affected bone may show some maturation in the form of lamellations.

\section{Periapical Cementoosseous Dysplasia}

That the name of this condition continues to change (cementomas, multiple cementomas, periapical osteofibrosis, cemental dysplasia) underscores our ignorance of its etiopathogenesis. This is an common reactive/dysplastic process of unknown stimulus. Its significance lies in its clinical and microscopic confusion with more important neoplastic and inflammatory jaw lesions. It occurs at the apices of vital mandibular (especially incisors) teeth, predominantly in middle-aged women (4142). It is occasionally seen at the apex of posterior teeth, where it is more likely to be confused clinically with a periapical granuloma or cyst and microscopically, with fibroosseous disease. These lesions, unlike the typical anterior lesions, are likely to be biopsied. This asymptomatic process passes through several radiographic stages: lucent, mixed lucent-opaque, and opaque. This lesion is usually not biopsied or treated because the process is selflimited and is diagnostic on clinical-radiographic correlation. Microscopically, periapical cementoosseous dysplasia appears as a benign fibroosseous lesion. A benign fibroblastic matrix contains a heterogeneous distribution of new and old bone in the form of islands and trabeculae. Inflammatory cells are scant.

Florid cementosseous dysplasia is believed to be an exuberant form of periapical cementoosseous dysplasia (Fig. 16). It may affect the entire jaw (usually mandible) and may be seen in association with traumatic bone cysts. Florid cementosseous dysplasia appears microscopically as a benign fibroosseous lesion (Fig. 17). Bony islands and trabeculae are

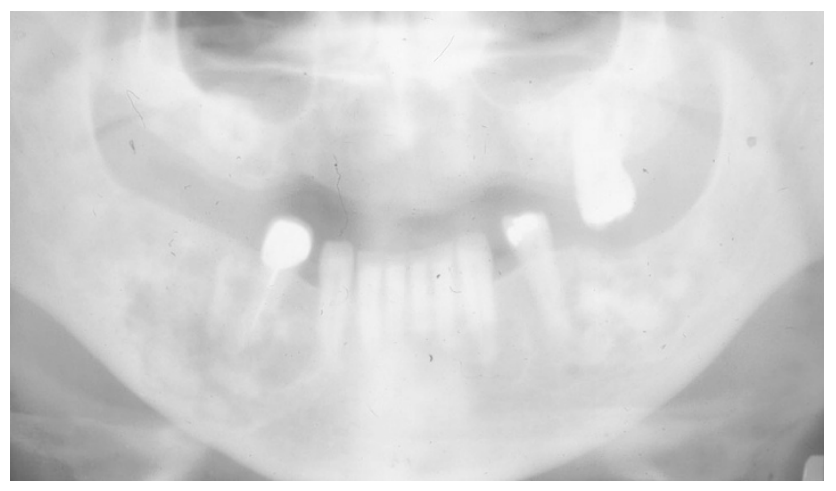

FIGURE 16. Florid osseous dysplasia of the entire body mandible. A mixed lucent and opaque pattern is evident in this case.

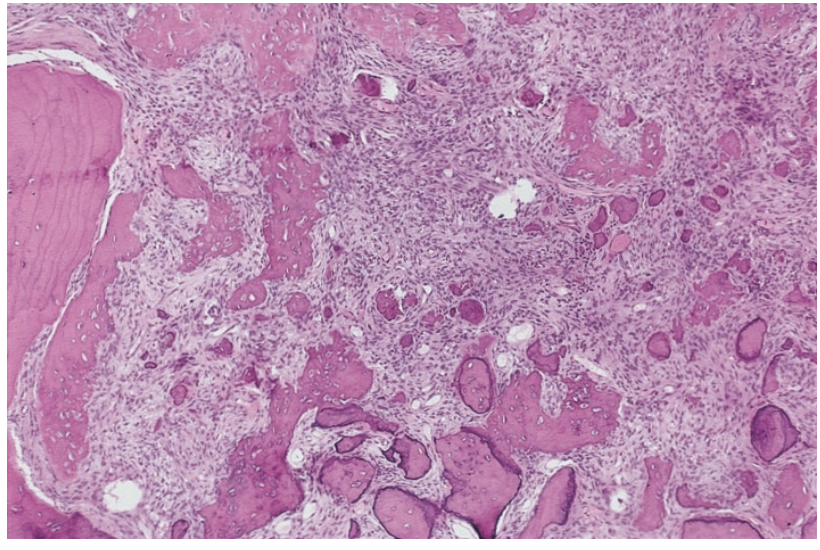

FIGURE 17. Heterogeneous pattern of florid osseous dysplasia. The appearance is fibroosseous, with both immature and mature bone present.

seen in a bland connective tissue matrix. Inflammatory cells are scant. Clinical correlation is necessary to make a definitive diagnosis. Unfortunately, florid osseous dysplasia may become secondarily inflamed, superimposing a chronic osteomyelitis on the process and making diagnosis more difficult $(46,47)$. Florid cementosseous dysplasia, like its periapical counterpart, requires no treatment, unless secondarily infected.

\section{Chronic Osteomyelitis}

Chronic osteomyelitis (including Garre's osteomyelitis) of the jaws is usually a low-grade inflammatory process that is often relatively asymptomatic. It is one of several lesions that may show microscopic overlap with fibroosseous lesions, especially ossifying fibroma and fibrous dysplasia. Inflammatory cells in chronic osteomyelitis may be quite scant, and there may be much new bone formation, giving the tissue a fibroosseous appearance. Both osteoblasts and osteoclasts are seen typically. The low-power microscopic pattern is heterogeneous, with new bony trabeculae admixed with more mature lamellated bone. The new bone is of irregular size, shape, and distribution.

\section{Osteosarcomas}

Fibroblastic osteosarcoma and central low-grade osteosarcoma may be a consideration in the differential diagnosis of fibroosseous jaw lesions because of the relatively well-differentiated and fibrous nature of these lesions (48-51). Definitive diagnosis is based upon hematoxylin and eosin microscopy taken in an appropriate clinical context. Diagnosis of fibroblastic osteosarcoma and central low-grade osteosarcomas requires the finding of atypical cells in association with immature, haphazardly distributed osteoid. Peripheral margins are usually poorly defined. Central low-grade osteosarcomas typically 
have a prolonged course and a correspondingly good prognosis. Transformation to a higher grade osteosarcoma may be seen many years after the original diagnosis. Prognosis also worsens with this event because of a more aggressive behavior and increased risk of metastasis.

\section{CENTRAL GIANT CELL GRANULOMA AND OTHER GIANT CELL LESIONS OF THE JAWS}

Central giant cell granuloma (CGCG) appears to be a lesion that is unique to the jaws, although so-called giant cell reaction of the hands and feet shares many features. CGCG was formerly regarded as a reparative process and was, accordingly, called central giant cell reparative granuloma (51). Although this is not a granulomatous inflammatory process, the term granuloma has persisted in this case because of tradition/habit. Although many investigators believe that CGCG should be classified as a reactive lesion, numerous documented aggressive and recurrent cases suggest that it may behave as a neoplasm. There is currently no way to predict, either clinically or microscopically, which lesions will behave badly.

CGCGs occur typically in the second and third decades (mean age of approximately 25 years). Females are more frequently affected than males. CGCG has a predilection for the mandible, especially the body and anterior portions of the jaw. The lesion is radiolucent and usually multilocular. Resorption and/or movement of teeth may be seen, and penetration of jaw cortex may occur. Most patients are asymptomatic, although pain or paresthesia may be a presenting complaint, particularly in aggressive lesions. Recurrences are more likely to be seen in children than adults. Surgery has been the treatment of choice, although alternative medical therapy with calcitonin injections has shown some promising results in reducing the size of large lesions. A less rational therapy of corticosteroid injections has been advocated by some who believe that CGCGs are reactive lesions.

Microscopically, a number of patterns may be seen (Fig. 18). The stroma may vary from vascular

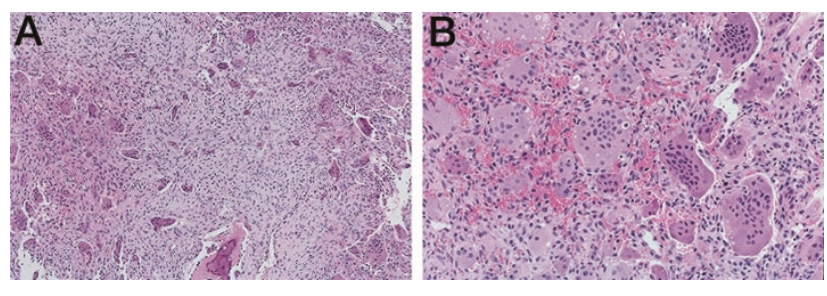

FIGURE 18. Two central giant cell granulomas. Left, the usual heterogeneous low-power appearance of the lesions. Right, giant cells can occasionally be relatively large, evenly distributed, and contain many nuclei. to fibrotic to myxoid in appearance. New bone, rimmed by osteoid, may be present, particularly at the periphery of the lesion. Recent and old hemorrhage is typically found, but necrosis is not seen. The dominant stromal cells are fibroblastic in origin. They are round, oval, or spindle in shape. They may be particularly numerous, and mitotic figures may be frequently seen (no prognostic significance). Although a heterogeneous pattern consisting of groups of giant cells separated by fibroblastic areas is typical of CGCGs, homogeneous patterns, in which large numbers of giant cells are evenly distributed throughout the lesion, are seen. The giant cells (CD68 positive) themselves vary in size, shape, and number. None of the histologic or immunohistologic features yet described have allowed separation of aggressive from nonaggressive lesions. CGCG appears to be a tumor in which osteoclasts or their precursors are recruited into a predominantly fibroblastic field (52-53). The fibroblasts are in cell cycle and may be responsible for production of cytokines or growth factors that support tumor growth.

The aggressive, recurrent (50-60\%) giant cell tumor of long bone (GCT), which is generally believed to be an entity that is separate from the CGCG, probably makes a rare appearance in the jaws. Because CGCG and GCT have overlapping histopathologic features, separation of these two lesions can be difficult. Some features that suggest GCT over CGCG include very large giant cells, large numbers of nuclei in giant cells, central aggregation of giant cell nuclei, diffusely distributed giant cells, high stromal cellularity, and necrosis. Microscopic differential diagnosis of CGCG look-alikes include aneurysmal bone cyst, hyperparathyroidism, and cherubism, all of which can be considered rare in the jaws relative to the frequency of occurrence of CGCG. Microscopically, aneurysmal bone cyst is characterized by large sinusoidal spaces lined by connective tissue with giant cells. Hyperparathyroidism is essentially identical to that of CGCG; however, lab values are altered (elevated serum calcium and parathormone), and the radiographic picture can be distinctive (multiple lesions and loss of lamina dura around roots of teeth). Cherubism appears microscopically indistinguishable from CGCG, except occasionally, when a fairly characteristic condensation of perivascular collagen is evident. Clinicopathologic correlation (children, autosomal dominant, bilateral multilocular jaw lucencies) is definitive.

\section{REFERENCES}

1. Meara JG, Shah S, Li KK, Cunningham MJ. The odontogenic keratocyst: a 20-year clinicopathologic review. Laryngoscope $1998 ; 108: 280-3$. 
2. Li TJ, Browne RM, Prime SS, Paterson IC, Matthews JB. p53 expression in odontogenic keratocyst epithelium. J Oral Pathol Med 1996;25:249-55.

3. LoMuzio L, Staibano S, Pannone G, Bucci P, Nocini, P, Bucci E, et al. Expression of cell cycle and apoptosis-related proteins in sporadic odontogenic keratocysts and odontogenic keratocysts associated with the nevoid basal cell carcinoma syndrome. J Dent Res 1999;78:1345-53.

4. Piattelli A, Fioroni M, Santinelli A, Rubini C. Expression of proliferating cell nuclear antigen in ameloblastomas and odontogenic cysts. Oral Oncol 1998;34:408-12.

5. Crowley TE, Kaugars GE, Gunsolley JC. Odontogenic keratocysts: a clinical and histologic comparison of the parakeratin and orthokeratin variants. J Oral Maxillofac Surg 1992;50 22-6.

6. Aszterbaum M, Rothman A, Johnson RL, Fisher M, Xie J, Bonifas JM, et al. Identification of mutations in the human PATCHED gene in sporadic basal cell carcinomas and in patients with the basal cell nevus syndrome. J Invest Dermatol 1998;110:885-8.

7. Cohen M. Nevoid basal cell carcinoma syndrome: molecular biology and new hypothesis. Int J Oral Maxillofac Surg 1999; 28:216-23.

8. Lench NJ, Telford EAR, High AS, Markham AF, Wicking C, Wainwright BJ, et al. Characterization of human patched germline mutations in nevoid basal cell carcinoma syndrome. Hum Genet 1997;100:497-502.

9. Lench NJ, High AS, Markham AF, Hume WJ, Robinson PA. Investigation of chromosome 9q22.3-q31 DNA marker loss in odontogenic keratocysts. Oral Oncol 1996;32B:202-6.

10. vanHeerden WFP, Raubenheimer EJ, Turner ML. Glandular odontogenic cyst. Head Neck 1992;14:316-20.

11. Lam KY, Chan AC, Wu PC, Chau KY, Tideman H, Wei W. Desmoplastic variant of ameloblastoma in Chinese patients. Br J Oral Maxillofac Surg 1998;36:129-34.

12. Schafer DR, Thompson LD, Smith BC, Wenig BM. Primary ameloblastoma of the sinonasal tract: a clinicopathologic study of 24 cases. Cancer 1998;82:667-74.

13. Mori M, Kasai T, Nakai M, Sato K, Takeuchi H, Takai Y, et al. Dentinogenic ghost cell tumor: histologic aspects, immunohistochemistry, lectin binding profiles, and biophysical studies. Oral Oncol 2000;36:134-43.

14. Carvalhais J, Aguiar M, Araujo V, Araujo N, Gomez R. P53 and MDM2 expression in odontogenic cysts and tumors. Oral Dis 1999;5:218-22.

15. Kumamoto H, Ooya K. Immunohistochemical analysis of Bcl-2 family proteins in benign and malignant ameloblastomas. J Oral Pathol Med 1999;28:343-9.

16. Li TJ, Browne RM, Matthews JB. Expression of proliferating cell nuclear antigen (PCNA) and Ki-67 in unicystic ameloblastoma. Histopathology 1995;26:219-28.

17. Mitsuyasu T, Harada H, Higuchi Y, Kimura K, et al. Immunohistochemical demonstration of bcl-2 protein in ameloblastoma. J Oral Pathol Med 1997;26:345-8.

18. Myoken Y, Okamoto T, Sato JD, Takada K. Immunohistochemical localization of fibroblast growth factor-1 (FGF-1) and FGF-2 in cultured human ameloblastoma epithelial cells and ameloblastoma tissues. J Oral Pathol Med 1995;24:38792.

19. Ong'uti MN, Cruchley AT, Howells GL, Williams DM. Ki-67 antigen in ameloblastomas: correlation with clinical and histological parameters in 54 cases from Kenya. Int J Oral Maxillofac Surg 1997;26:376-9.

20. Piattelli A, Fioroni M, Santinelli A, Rubini C. Expression of proliferating cell nuclear antigen in ameloblastomas and odontogenic cysts. Oral Oncol 1998;34:408-12.

21. Pripatnanont $\mathrm{P}$, Song $\mathrm{Y}$, Harris M, Meghij S. In situ hybridization and immunohistochemical localization of osteolytic cytokines and adhesion molecules in ameloblastomas. J Oral Pathol Med 1998;27:496-500.

22. Slootweg PJ. p53 protein and Ki-67 reactivity in epithelial odontogenic lesions. An immunohistochemical study. J Oral Pathol Med 1995;24:393-7.

23. Takahashi H, Fujita S, Yamabe S. Comparison of proliferating cell nuclear antigen expression in odontogenic keratocyst and ameloblastoma: an immunohistochemical study Anal Cell Pathol 1998;16:185-92.

24. Li TJ, Kitano M, Arimura K, Sugihara K. Recurrence of unicystic ameloblastoma: a case report and review of the literature. Arch Pathol Lab Med 1998;122:371-4.

25. Olaitan AA, Adekeye EO. Unicystic ameloblastoma of the mandible: a long-term follow-up. J Oral Maxillofac Surg 1997;55:345-8.

26. Philipsen HP, Reichert PA. Unicystic ameloblastoma. A review of 193 cases from the literature. Oral Oncol 1998;34 317-25.

27. Rosenstein T, Pogrel MA, Smith RA, Regezi JA. Cystic ameloblastoma-behavior and treatment. J. Oral and Maxillofac Surg 2001;59;1311-6.

28. Lau SK, Tideman H, Wu PC. Ameloblastic carcinoma of the jaws. A report of two cases. Oral Surg Oral Med Oral Pathol Oral Radiol Endod 1998;85:78-81.

29. Infante-Cossio P, Hernandez-Guisado JM, FernandezMachin P, Garcia-Perla A, Rollon-Mayordoma A, GutierrezPerez JL. Ameloblastic carcinoma of the maxilla: a report of 3 cases. J Craniomaxillofac Surg 1998;26:159-62.

30. Aviel-Ronen S, Liokumovich S, Rahima D, Polak-Charcon S, Goldberg I, Horowitz A. The amyloid deposit in calcifying epithelial odontogenic tumor is immunoreactive for cytokeratins. Arch Pathol Lab Med 2000;124:872-6.

31. Maiorano E, Altini M, Favia G. Clear cell tumors of the salivary glands, jaws, and oral mucosa. Semin Diagn Pathol 1997;14:203-12.

32. Yamamoto H, Inui M, Mori A, Tagawa T. Clear cell odontogenic carcinoma: a case report and literature review. Oral Surg Oral Pathol Oral Med Oral Radiol Endod 1998;86:86-9.

33. Lombardi T, Lock C, Samson J, Odell EW. S-100, alphasmooth muscle actin and cytokeratin 19 immunohistochemistry in odontogenic and soft tissue myxomas. J Clin Pathol 1995;48:759-62.

34. Lo Muzio L, Nocini P, Pavia G, Procaccini M, Mignogna MD. Odontogenic myxoma of the jaws: a clinical, radiologic, immunohistochemical, and ultrastructural study. Oral Surg Oral Med Oral Pathol Oral Radiol Endod 1996;82:426-33.

35. Zhao M, Lu Y, Takata T, Ogawa I, Miyauchi M, Mock D, et al. Immunohistochemical and histochemical characterization of the mucosubstances of odontogenic myxoma: histogenesis and differential diagnosis. Pathol Res Pract 1999;195: 391-7.

36. Allen CM, Hammond H, Stimson P. Central odontogenic fibroma, WHO type. Oral Surg Oral Med Oral Pathol 1992; 73:62-6.

37. Gardner DG. Central odontogenic fibroma: current concepts. J Oral Pathol Med 1996;25:556-61.

38. Handlers JP, Abrams AM, Melrose RJ, Danforth R. Central odontogenic fibroma: clinicopathologic features of 19 cases and review of the literature. J Oral Maxillofac Surg 1991;49: $46-54$.

39. Hasimoto K, Mase N, Iwai K, Shinoda K, Sairenji E. Desmoplastic fibroma of the maxillary sinus. Oral Surg Oral Med Oral Pathol 1991;72:126-32.

40. Taconis WK, Schutte H, van der Heul R. Desmoplastic fibroma of bone: a report of 18 cases. Skeletal Radiol 1994;23 283-8.

41. Su L, Weathers DR, Waldron CA. Distinguishing features if focal cemento-osseous dysplasia and cemento-ossifying fi- 
bromas: I. A pathologic spectrum of 316 cases. Oral Surg Oral Med Oral Pathol Oral Radiol Endod 1997;84:301-9.

42. Su L, Weathers DR, Waldron CA. Distinguishing features of focal cemento-osseous dysplasia and cemento-osseous fibromas. II. Oral Surg Oral Med Oral Pathol Oral Radiol Endod 1997;84:540-9.

43. Slootweg PJ, Muller H. Juvenile ossifying fibroma. Report of four cases. J Craniomaxillofac Surg 1990;18:125-9.

44. Slootweg PJ, Panders AK, Koopmans R, Nikkels PGJ. Juvenile ossifying fibroma. An analysis of 33 cases with emphasis on histopathological aspects. J Oral Pathol Med 1994;23:385-8.

45. Camilleri AE. Craniofacial dysplasia. J Laryngol Otol 1991; 105:662-6.

46. Groot RH, van Merkesteyn JP, Bras J. Diffuse sclerosing osteomyelitis and florid osseous dysplasia. Oral Surg Oral Med Oral Pathol Oral Radiol Endod 1996;82:360-1.

47. Schneider LC, Mesa ML. Differences between florid osseous dysplasia and chronic diffuse sclerosing osteomyelitis. Oral Surg Oral Med Oral Pathol 1990;70:308-12.
48. Bertoni F, Dallera P, Bacchini P, Marchetti C, Campobassi A. The Istituto Rizzoli-Beretta experience with osteosarcoma of the jaws. Cancer 1991;68:1555-63.

49. Tanzawa H, Uchiyama S, Sato K. Statistical observation of osteosarcoma of the maxillofacial region in Japan. Oral Surg Oral Med Oral Pathol 1991;72:444-8.

50. Vege D, Borges A, Aggrawal K, Balasubramaniam G, Parikh D, Bhaser B. Osteosarcoma of the craniofacial bones. J Craniomaxillofac Surg 1991;19:90-3.

51. Whitaker SB, Waldron CA. Central giant cell lesions of the jaws. Oral Surg Oral Med Oral Pathol 1993;75:199-208.

52. Lim L, Gibbins JR. Immunohistochemical and ultrastructural evidence of a modified microvasculature in the giant cell granuloma of the jaws. Oral Surg Oral Med Oral Pathol Oral Radiol Endod 1995;79:190-8.

53. O'Malley M, Pogrel M, Stewart JCB, Silva RG, Regezi JA. Central giant cell granulomas of the jaws: phenotype and proliferation-associated markers. J Oral Pathol Med 1997;26: 159-63. 